\title{
Qualidade Total na Formação Profissional: do Texto ao Contexto
}

\author{
Maria Laura P. Barbosa Franco \\ Fundação Carlos Chagas (FCC) \\ Pontifícia Universidade Católica de São Paulo (PUC-SP)
}

Discute o conceito de qualidade de ensino, sua relação com o significado de qualidade total e seus desdobramentos para a educação; questiona a dicotomia quantidade x qualidade no âmbito do sistema educacional brasileiro; explica o vínculo que se estabelece entre os indicadores implícitos na concepção de ensino de qualidade e as demandas provenientes dos novos processos de produção e suas exigências para a formação profissionai.

\section{Introdução}

A década de 90 coloca novos desafios aos educadores. Não apenas o Brasil, mas, também, toda a América Latina encontra-se, mais uma vez, no impasse de rever suas prioridades para a educação, nos marcos de novas dinâmicas de desenvolvimento.

Tais dinâmicas delineiam-se, por um lado, em um contexto de recursos limitados e, por outro, no bojo de um cenário de avanço tecnológico e de intercâmbio científico, em uma perspectiva regional e, sobretudo, internacional.

Entre outras palavras, a planificação, a prática educativa e suas relações com o mercado, a competitividade, as formas de gestão, a democratização do saber e a necessidade de formação de grupos de 
excelência são aspectos críticos que requerem atenção renovada e prospectiva.

Neste programa, a educação e a aquisição de conhecimentos passam a ser vistas como elementos fundamentais, enquanto possibilidade de desenvolvimento econômico, político e social. Mais enfaticamente, a capacitação de recursos humanos e, especificamente, a formação de técnicos ganham importância redobrada. Aqui, estamos sendo atropelados pela tentativa da imposição de um modelo normativo, hegemônico e gestado nos países de capitalismo avançado que, por hipótese, já atingiram o estágio da "modernidade", via incorporação de novas tecnologias.

No entanto, apesar dos propalados avanços tecnológicos, da busca de novos mecanismos de acumulação do capital - que rapidamente se internacionaliza - e de novas formas de gerenciamento institucional e empresarial (seja nos setores da produção ou nos de serviços), o capitalismo está novamente em crise. E, desta vez, como diz Lucila Machado, trata-se de uma crise bem mais profunda (como aquela decorrente da depressão de 1929, por exemplo), à medida que envolve elementos que colocam em risco a própria capacidade de manutenção e de realização do capitalismo (Machado, 1993).

E certo que diferentes estratégias têm sido analisadas e, por tentativa, implantadas, no sentido da superação dessa crise que é de natureza estrutural e de dimensão mundial.

Dentre tais estratégias, algumas estão especificamente direcionadas ao redimensionamento das propostas a serem elaboradas para a formação de técnicos e para a qualificação do trabalhador. Nessa vertente, o significado a ser atribuído ao reconhecimento da qualidade dessa formação assume renovada importância.

Nos limites deste trabalho, optamos por delinear algumas questões relativas à concepção de qualidade do ensino (em geral, e, em especial, do ensino técnico) levando em conta a necessidade de: 
- enfrentar esse debate de uma maneira contextualizada;

- privilegiar uma reflexão teórica;

— e, principalmente, enfocar a discussão acerca dos indicadores preconizados, hoje, para a definição de qualidade do ensino, no âmbito dos pressupostos que os sustentam.

\section{A qualidade do ensino e seus desafíos}

\section{O DESAFIO EMPÌRICO}

A qualidade do ensino tradicionalmente se apresenta como um problema para a América Latina, quando se supõe resolvido o problema da oferta. Entre nós, acreditamos que é preciso enfrentar essa problemática, no bojo de um caótico e perverso panorama de acesso à educação formal, que hoje se mostra longe de estar resolvido.

Nos anos 70, demandas sociais e econômicas, exercendo forte pressão sobre os setores educacionais, exigiram ampliação das oportunidades de acesso ao ensino formal. Nesse sentido, efetuaram-se esforços - que, em última instância, representaram apenas acomodações às condições existentes - para aumentar a oferta de matrículas nas instituições da rede pública.

Relatórios oficiais mostravam, já no início da década de 80 , resultados que, à primeira vista, pareciam auspiciosos quanto ao número de matrículas iniciais. De fato, sob uma perspectiva quantitativa, os dados atestavam porcentagens promissoras em relação ao acesso à escola, em todos os niveis. Mesmo assim, já naquele momento, muitos analistas empenharam-se em denunciar as perversas estratégias que tornariam essa "democratização" superficial e inconsistente, uma vez que se apoiavam: na criação de classes superlotadas; em escolas funcionando em até cinco turnos; no sensível rebaixamento salarial de professores etc. Tais dados, entre outros, permitiam prognosticar conseqüências desastrosas para a qualidade do ensino. 
Atualmente, e a partir de novos e bem mais sofisticados procedimentos, alguns pesquisadores constatam que $95 \%$ das crianças de cada geração têm acesso à escola. Na opinião dos mesmos, a falta de vagas deveria, assim, deixar de figurar no roi dos fatores explicativos da ineficiência da educação brasileira, à medida que tal ineficiência estaria relacionada principalmente às altas taxas de repetência escolar. Concomitantemente, outros dados também atestam não existir elevada evasão precoce. Assim, a evasão aparece inflacionada (nos registros oficiais) porque, quando a reprovação se torna iminente, os alunos desistem, ou são induzidos a desistir da escola naquele ano, mas rematriculam-se no ano seguinte. Continuam, portanto, sendo atendidos pelo sistema educacional, ainda que pareçam ser por ele excluídos.

Esses argumentos trazem o benefício de permitir que se enfrente, com mais firmeza, a questão da repetência e da pesada responsabilidade que cabe à escola no pretenso fracasso dos alunos. Da mesma forma, ventila-se, com muita propriedade, o conceito da "cultura da repetência", que consiste no desdobramento, no âmbito escolar, dos preconceitos que se desenvolvem em relação às camadas populares, e que, gerados a partir de relações de produção perversas, permeiam toda a sociedade, refletindose, pois, na escola.

Apesar da pertinência das considerações anteriores, acreditamos ser temerário concluir que a infra-estrutura e os insumos destinados à educação sejam suficientes para conseguir resolver o problema da qualidade do ensino com os recursos que já possuímos. Isso porque devemos começar indagando: de que escolas estamos falando, quando afirmamos que o acesso à educação está praticamente garantido a 95\% das crianças de cada geração?

Uma parte da pesquisa, concluída em dezembro de 1993 pelo Instituto de Pesquisa e Economia Aplicada (IPEA) do Ministério do Planejamento, detalhou as condições fisicas de 192 mil estabelecimentos de ensino do País, obtendo resultados extremamente negativos. Mostrou 
que $25 \%$ deles não têm nenhum banheiro. Em 27\% não existe sequer água, nem de poço. No meio rural esse número sobe para $33 \%$, e $48 \%$ não dispõem de energia elétrica, nem mesmo de bancos suficientes para os alunos, obrigados a dividir carteiras ou a sentar no chão (Fôlha de $S$. Paulo, 1994).

Se nos reportamos a dados mais qualitativos, constatamos que um expressivo número de escolas rurais isoladas, principalmente no Nordeste, são espaços que funcionam sob o rótulo de "Escola", mas que, para serem admitidas como tal, é preciso deixar de lado o conceito tradicional que se tem de uma instituição de educação formal. Estabelecidas nas pobres residências das professoras, tais "escolas" estão organizadas em classe multisseriada, gerando para os alunos uma dupla tarefa: os mais velhos não apenas auxiliam os mais novos nos trabalhos escolares, como, também, em muitos casos, ajudam na preparação da merenda e até nos cuidados com os filhos das professoras. Estas, por sua vez, na sua grande maioria, recebem salários apenas "simbólicos" e, sem formação adequada, disputam uma vaga para serem "professoras", principalmente pelos "beneficios" que, por hipótese, terão direito de usufruir junto ao INSS.

Nas regiões mais desenvolvidas do Brasil, serão "escolas" aquelas que funcionam em cinco turnos por dia, cujos baixos salários afastam os profissionais qualificados, abrindo constantes vazios nos quadros funcionais? Ainda, serão "escolas" aquelas cujos problemas, ecos de nossas profundas mazelas sociais, extrapolam, de muito, as questões pedagógicas? Nesse sentido, é pertinente transcrever aqui o depoimento da diretora de um estabelecimento situado entre duas violentas e populosas favelas no Rio de Janeiro: "Aqui temos 2.300 alunos que já estão acostumados com os tiroteios entre as quadrilhas de traficantes e os policiais. Mandamos construir um muro alto para protegê-los, mas ele vivia sempre cravejado de balas até que um dia caiu. Eles (os alunos) já estão acostumados. Aprenderam a se defender quando percebem algo de anormal. Mas 
continuam vindo à escola. Não querem que as aulas sejam suspensas" (Veja, 1993). Em outra escola carioca, os traficantes ordenaram a suspensão das aulas porque queriam usar o espaço para venda de drogas. Professores apavorados foram focalizados em telejornal e admitiam terem sido obrigados a mandar os alunos para casa.

Enfim, podemos minimizar a incidência de fatores materiais na insuficiência do sistema escolar quando, em um Estado rico como São Paulo, reiteradas greves de professores (que lutam contra salários realmente iníquos e por melhores condições de ensino) ocorrem freqüentemente, deixando milhões de crianças sem aula?

Acreditamos que, no Brasil, o efetivo acesso à educação formal está longe de ser resolvido. Diminuir a importância das dificuldades materiais e sociais da escola e do processo escolar, insistindo-se unicamente na dimensão pedagógica, pode redundar em uma visão simplista e linear.

Em nosso entender, a consideração dos aspectos anteriores representa o primeiro passo, quando a tarefa é discutir qualidade do ensino. Discussão que se efetua em um momento em que, por um lado, a educação se encontra na encruzilhada do difícil convívio que se estabelece entre modalidades de ensino-aprendizagem tradicionais e arcaicas e o fascínio da Ciência e das novas tecnologias que envolvem a informática, a telecomunicação, o vídeo, a televisão a cabo, as redes eletrônicas (cada vez mais em expansão), os bancos de dados etc; por outro lado, assistimos ao surgimento de uma sociedade na qual os conhecimentos científicos e tecnológicos - e não mais o tamanho do exército ou a dimensão das fábricas - parecem ser os elementos mais significativos para o desenvolvimento do mundo em que vivemos, e ao antigo apelo à educação — agora, porém, mais intenso — como redentora e panacéia para a saída do atoleiro econômico e para a superação dos males sociais. Retóricas vazias que, mesmo se bem intencionadas, pressupõem, equivocadamente, a existência de indispensáveis precondições básicas, de um determinado patamar de 
desenvolvimento e de um acesso igualitário aos bens socialmente produzidos, muito além da situação com a qual, em verdade, convivemos.

\section{O DESAFIO TEÓRICO}

A qualidade do ensino pressupõe um julgamento de mérito que se atribui tanto ao processo quanto aos produtos decorrentes das ações educacionais. Implica, pois, um juízo de valor, mas não qualquer tipo de juízo.

Sob essa ótica, Verônica Risopatron ( 1991 ) destaca alguns aspectos a serem observados quando a tarefa é definir qualidade do ensino e seus respectivos indicadores. Com razão, alerta que estamos diante de um desafio teórico, à medida que o conceito de qualidade é um significante $\mathrm{e}$ não um significado. Daí, sua inerente ambigüidade e a dificuldade de abordar essa problemática com clareza e objetividade. "A consciência da ambigüidade deste termo surge porque se espera que ele seja definido a partir de um único significado. Sem dúvida, o conceito de qualidade assim como do belo, do bom e da morte - é um significante que pode adquirir muitos significados" (Risopatron, 1991, p. 15).

$\mathrm{O}$ conceito de qualidade, enquanto significante, é um conceito historicamente produzido e, neste caso, não pode ser definido em termos absolutos. Pressupõe uma análise processual, uma dinâmica, a recuperação do específico e o respeito às condições conjunturais. E, pois, um conceito fixado a partir de um arbitrário sociocultural e orientado por diferentes expectativas que incorporam demandas diversificadas e mutáveis ao longo dos tempos.

Além disso, não é um conceito neutro. Ao contrário, reflete um posicionamento político e ideológico perceptível, seja para a definição da qualidade do ensino, seja para o encaminhamento de propostas que se corporificam na explicitação de seus indicadores. 
Devido à característica dual do ensino médio no Brasil, os indicadores de sua qualidade oscilaram, ao longo dos tempos, entre enfatizar a capacitação dos jovens para o prosseguimento dos estudos, e permitir a conclusão da formação técnico-profissional, encarada, neste caso, como objetivo terminal.

Sob a ótica da formação técnica, sua discussão tem sido efetuada no compasso da relação que se estabelece entre educação e trabalho. A partir deste eixo, são bastante conhecidos os promissores encaminhamentos que, em nível teórico, tentam equacionar tal relação, tendo como substrato os interesses dos trabalhadores, bem como os diferentes questionamentos que circunscrevem esta problemática. Vamos, portanto, retomá-los apenas sucintamente.

No bojo desses questionamentos, na década de 70, o alvo principal foi a profissionalização imposta, de maneira universal e compulsória, ao ensino de $2^{\circ}$ grau, mediante a Lei 5.692, em 1971. Vários argumentos apoiaram tais críticas, desde os que se deixaram levar por razões pragmáticas e conjunturais, até aqueles, mais elaborados, que buscaram respaldo em pressupostos teóricos pertinentes à temática. No conjunto do primeiro grupo, destacam-se os discursos que associam a falência da profissionalização (tal como concebida) à incapacidade do sistema educacional em absorvê-la. Incapacidade que se justifica pela falta de recursos físicos e de equipamentos disponíveis, pela carência de pessoal qualificado ou mesmo pelo desinteresse demonstrado por muitos estabelecimentos de ensino em relação às propostas profissionalizantes.

Do ponto de vista teórico, as críticas, em oposição às abordagens "do capital humano", constataram o equívoco de uma profissionalização estreita e a orientação dada à preparação para o trabalho, sem considerar que educação e trabalho estão submetidos a processos cíclicos nitidamente diferenciados.

No cipoal de incertezas e de indefinições, surge como uma nova proposta a organização dos currículos, para a educação técnica, em torno 
do trabalho visto como "principio educativo". Essa abordagem ganha força no final da década de 80 e se direciona para a oferta de uma educação que permita ao aluno apropriar-se tanto de uma nova concepção de ciência quanto de uma visão ampla e crítica dos processos de trabalho e da produção e seu impacto sobre a sociedade. Apesar da carência de uma sistematização, capaz de lhe imprimir contornos mais definidos, tal abordagem teve o mérito de iniciar um debate acerca da educação unitária e de recrudescer o questionamento acerca de um ensino médio segmentado e excludente, por sua própria configuração.

A década de 90 inicia-se com novas e bem mais complexas questões. Aprofunda-se a discussão acerca da contínua referência aos mecanismos do mercado como os grandes orientadores das políticas educacionais. A essa referência acrescenta-se o debate sobre o recorrente apelo à "modernidade" e à "modernização", as quais, ainda que simbolicamente representadas, como diz Casassus, são aspirações comuns e consensuais de toda a América Latina. Sua busca parece substituir o discurso da revolução social e o ideário desenvolvimentista e surge como uma possibilidade de transformação política e econômica (Casassus, 1993). Transformação que implica o repensar das propostas de formação de recursos humanos diante da contradição que se estabelece entre um processo de industrialização heterogênea e desigual (no qual o segmento mais moderno se utiliza de tecnologias sofisticadas) e a realidade de um contexto permeado pela existência de uma força de trabalho barata e abundante e penalizado pelo subemprego e pelo desemprego. Daí, a dupla exigência em, por um lado, organizar formas institucionais para a formação de técnicos e, ao mesmo tempo, propiciar a educação básica a um grande contingente da população dela excluída.

As colocações anteriormente delineadas (ainda que sucintamente) fornecem pistas para a análise de dois importantes corolários que delas derivam.

Por um lado, remete-nos ao exame das pressões nacionais e internacionais que, impostas por interesses globalizantes, passam a imprimir 
sucessivas modificações no que se refere à forma considerada adequada para a formação de técnicos qualificados para o enfrentamento das exigências atuais - aspecto que será retomado no item subseqüente, quando nos reportamos à discussão sobre qualidade total.

Por outro lado, acenam para a importância da definição de prioridades para a educação, especialmente em um país como o nosso cujos dados atestam: 150 milhões de habitantes, dentre estes 40 milhões de pessoas vivendo em condições de extrema pobreza; 48 milhões de analfabetos e cerca de 10 milhões de crianças fora da escola (IBGE, 1990).

Quanto à questão da definição de prioridades, vamos apenas aproveitar o momento para "pensar alto".

Sem dúvida, investir no ensino básico é indispensável, uma vez que é ele que constitui a porta de entrada para a democratização do saber e a possibilidade de fortalecer a qualidade dos níveis subseqüentes.

Todavia, não podemos cair na armadilha dos argumentos lineares e mecanicistas que procuram demonstrar, entre outras coisas, que a profissionalização, por si própria, é uma idéia errada; que se utilizam das dificuldades relativas à inserção de egressos de escolas técnicas no mercado para justificar a inadequação entre educação e trabalho; que falam a favor da maior eficiência da "pedagogia da fábrica", em detrimento da formação de técnicos no interior do sistema formal de ensino; que denigrem e tripudiam as propostas curriculares fragmentadas e o adestramento limitado, mas não elaboram, com a devida profundidade, encaminhamentos de propostas mais amplas e mais eficazes para a apropriação de um saber técnico competente. Ou seja, aquele saber que realmente concentre a possibilidade de elevar um sujeito desprovido de instrumentos específicos à condição de cidadão, o qual passa a deter maior poder de barganha no mercado de trabalho, através do domínio de conhecimentos, habilidades e atitudes compatíveis com as demandas características do seu tempo e historicamente definidas.

Enfim, há que se esquivar das armadilhas vistas como conjunturais e procurar identificar as razões mais profundas subjacentes às políticas 
educacionais que ora enfatizam o fortalecimento da formação de técnicos e de especialistas, ora buscam procedimentos mediadores para o enfraquecimento dessa mesma formação.

\section{O DESAFIO DOS PRESSUPOSTOS}

Como já dissemos, o termo "qualidade" é historicamente situado e supõe a incorporação de diferentes significados. Daí, quando indagamos acerca da qualidade de qualquer objeto, é possível identificar elementos observáveis que permitam (ou não) a aferição de seus padrões de qualidade. Assim, por exemplo, pode-se testar a durabilidade de determinado produto, a adequação de diferentes aparelhos às funções às quais se destinam; a pertinência de estratégias que auxiliam na aprendizagem de conceitos, na inculcação ideológica ou na disseminação de idéias alienantes.

Nesses casos, tanto o processo de desenvolvimento quanto o produto final podem ser submetidos a um controle de qualidade e, em geral, a avaliação tende a ser consensual. Todavia, quando indagamos: "qualidade para quem?, não há lugar para pretensões normativas nem para supor universalização de interesses.

A diversificação dos indicadores de qualidade que se colocam no sistema educacional sustenta tal afirmação. Exemplificando: a partir de critérios sabidamente exógenos (porém diferenciados em suas bases), a qualidade de uma escola de $2^{\circ}$ grau de elite tem sido, seguidamente, consagrada - principalmente nos centros urbanos mais desenvolvidos - pela quantidade de ex-alunos (sempre exibidos nos meios de comunicação) que conseguiram boas colocações para o ingresso no ensino superior (em universidades também de elite); para os egressos de escolas técnicas de nível médio (tendo como referência, neste caso, também os centros urbanos mais desenvolvidos e, em especial, as escolas das redes vinculadas ao setor produtivo, como Senai, Senac, Señar), a obtenção de 
bons empregos, na respectiva área de formação, passa a ser um forte indicador para a avaliação da qualidade de tais escolas; já em escolas de $2^{\circ}$ grau de periferia, que funcionam no período noturno e que acolhem, em sua grande maioria, estudantes trabalhadores, os grosseiros índices de aprovação (em contraposição aos que indicam evasão e repetência) são sistematicamente expostos e considerados como suficientes para a atribuição de sua "qualidade"; no contexto mais geral do nosso sistema de ensino (permeado por instituições desprovidas de recursos), o domínio das primeiras letras e das operações matemáticas básicas parece ser o bastante a ser almejado e o possível a ser realizado.

\section{O que falar sobre qualidade total?}

No contexto dessa heterogeneidade, que reflete a desigualdade de acesso aos bens sociais, decorrente de um sistema econômico extremamente excludente, difunde-se (a cada dia com mais vigor) o discurso da "qualidade total" e indaga-se acerca de sua possível aplicabilidade na educação.

Do ponto de vista macropolítico e econômico, a busca da qualidade total, como diz Lucila Machado, aponta para "a salvação em direção ao paraíso celestial" (Machado, 1994, p.2).

Apropriando-nos de suas idéias (ao mesmo tempo pertinentes, analógicas, perspicazes e irônicas), concordamos que, na situação de flagelos - crise econômica, instabilidade financeira, subemprego, desemprego etc. - que se instalam no mundo e que penalizam, mais fortemente, a América Latina, fazer parte de um seleto grupo da elite mundial é, sem dúvida, aspiração comum de todos os países. Mais do que isso, o melhor mesmo deveria ser o primeiro no ranking competitivo do capitalismo internacional. Neste sentido, divulgam-se idéias doutrinárias acerca do conceito de "qualidade total".

Idealiza-se que "para salvar o Brasil é preciso salvar as empresas" Salvando-se o País, salva-se a humanidade. Os merecedores da graça serão 
aqueles que se mostrarem mais competentes, os que souberem aplicar eficazmente os princípios e métodos do sistema administrativo da qualidade total para a solução de seus problemas (Machado, 1994, p.2).

Não pretendemos, nos limites de nossos objetivos, aprofundar o significado de "qualidade total". Todavia, consideramos importante destacar alguns de seus princípios.

Por um lado, os meios de comunicação têm sido generosos em manter uma orquestrada propaganda para apresentar a "qualidade total" como o mais avançado símbolo da produtividade, da produção material e das atividades de bens e serviços (Machado, 1994). Por outro lado, reina uma evidente confusão conceitual acerca de tal expressão.

Como já dissemos, o termo "qualidade" é um significante impregnado de conotações valorativas. Da mesma forma, a expressão "qualidade total" incorpora diferentes significados, dependendo da ótica de quem a define e para quem se dirige. No entanto, nos discursos atualmente presentes acerca da expressão "qualidade total", advoga-se a favor de sua neutralidade objetiva. "Neutralidade" que, ancorada na lógica individualista de reconversão produtiva, escamoteia seu forte componente ideológico, ao deslocar para o terreno da responsabilidade pessoal a intensificação das já profundas contradições, exclusões e marginalizações sociais.

Nesse sentido, o entendimento do conceito de qualidade total está muito mais vinculado à compreensão de uma nova mentalidade empresarial, no que se refere às condições de produções e às técnicas de gestão, do que em relação à sua própria conceituação.

No que se refere às técnicas de gestão, a mentalidade embutida na concepção de "qualidade total" opõe-se ao arcaísmo e à rigidez dos modelos tayloristas e fordistas e assenta-se em princípios de flexibilidade e autonomia gerencial.

A partir desses princípios, definem-se seus principais componentes:

a) $\mathrm{O}$ uso do tempo de cada funcionário, durante o qual ele exibe comportamentos relativos a compromissos individuais, e de responsabi- 
lidade e solidariedade. A idéia é de que o uso do tempo seja "autocontrolado", tendo em vista uma participação compartilhada, na qual cada "colaborador" funcione como uma microempresa, sendo, portanto, necessário que cada segmento de uma unidade se conheça e com sua equipe de trabalho seja capaz de gerenciar seus próprios processos (produtos e serviços) e sua atuação funcional;

b) A combinação dos meios (recursos humanos, equipamento, informatização) para a produção de um determinado bem ou serviço, "o que, em última instância, definiria a função da produção";

c) A importância do cliente, cuja satisfação passa a ser a chave para a reestruturação de qualquer instituição pública ou privada. "Na administração taylorista e, até mesmo fordista, a produção era realizada na 'Ley de Say', à medida que os empresários ofertavam seus produtos sem o conhecimento prévio das reais necessidades dos consumidores, na crença de que toda oferta cria sua própria demanda. $\mathrm{O}$ caráter menos competitivo da indústria e a escassez de alternativas, por parte dos consumidores, faziam com que esta estratégia pudesse até dar certo. Hoje, os mercadores são muito mais seletivos e exigentes e a organização da produção exige o conhecimento prévio e detalhado do mercado" (Medici, 1993, p.32);

d) A implantação de mecanismos de avaliação em processo (com explicitação de critérios e definição de indicadores quantificáveis), tendo em vista:

- a aferição da qualidade intrínseca — custo, atendimento, moral da equipe, capacidade na rapidez de adaptações e na correção de distorções just in time;

- a mensuração da qualidade extrínseca, balizada por indicadores de produtividade e tendo como parâmetros a satisfação das necessidades e das expectativas dos clientes/consumidores;

e) em conseqüência, nessa nova filosofia, centrada na crença da "pseudo" autonomia e na responsabilidade pessoal pelo desenvolvimento de competências individuais, preconiza-se o estabelecimento de uma nova 
politica salarial diferenciada, baseada em índices de produtividade, solidariedade e cooperação.

Em que pese a racionalidade orgânica do discurso que se dissemina acerca da expressão "qualidade total", gostaríamos de questionar alguns de seus pressupostos (em especial, no que se refere aos desdobramentos para a educação) e chamar a atenção para a abstração implícita em suas bases de sustentação. Abstração que, na falta de referenciais concretos, pode vir a se constituir "na grande ameaça da próxima rodada da ciranda capitalista e cujos efeitos apenas começam a se esboçar neste final de século" (Dupas, 1994).

\section{Os desdobramentos para a educação}

A onda competitiva, para a saída da crise que o País atravessa, bate forte na praia da educação, em um momento em que o conhecimento e a formação de recursos humanos passam a ser vistos como eixos de transformação produtiva.

$\mathrm{Na}$ esteira do ideário liberal, tenta-se introduzir no sistema escolar os mecanismos de mercado com ênfase no controle e na avaliação; na remuneração por mérito; no apoio à livre iniciativa; na premiação por competência; na busca de maior racionalização administrativa etc.

Em especificó, para o ensino técnico, recorre-se à redefinição dos indicadores de qualificação (ou requalificação) profissional, tendo-se como horizonte a capacitação para a "modernidade", condição sequer atingida e nem mesmo conceitualmente compreendida, como já tivemos oportunidade de discutir mais profundamente em Franco (1994, cap.6).

É, também, no âmbito da formação profissional que se instala o conceito de qualidade total, cujos princípios deveriam se corporificar em um conjunto de procedimentos capazes de garantir a qualidade dos resultados e dos serviços, em contraposição às práticas tradicionais.

Ainda que redundante, é bom lembrar que - ao longo do tempo que estamos comprometidos com o estudo da relação entre educação e 
trabalho - já tivemos oportunidade de acompanhar os debates acerca da função social do ensino técnico em um contexto de transição democrática. Posteriormente, enfrentamos a discussão sobre a profissionalização do ensino médio, a questão do trabalho enquanto princípio educativo, as distorções do sistema educação-produção e, mais recentemente, o impacto das novas tecnologias na interface que caracteriza o binômio "modernidade" e crise.

Agora, com uma força disseminadora jamais vista, estamos sendo tomados de assalto pela propagação da idéia da integração entre escola e setor produtivo e pela introdução, na educação, da concepção de qualidade total.

A esse respeito, diria que, apesar do otimismo demonstrado por André Medici, ao explicitar os benefícios desta introdução (Medici, 1993), devo concordar com Lucila Machado, quando desnuda o ideário mistificador que está por trás dessa vinculação. A qualidade total emerge enquanto possibilidade de tornar o País competitivo e, para isso, "deve ingressar também o (sic) sistema escolar, para que as escolas se tornem exímias na solução de seus problemas. Problemas são nada mais nada menos que resultados indesejados. Então, é preciso garantir que o produto, o egresso dessa escola, não seja um resultado indesejado, não seja alguém que não se integre a esta cadeia competitiva, que não trilhe os caminhos da salvação! E que a escola contribua com o sistema, repassando custos menores além da qualidade do produto esperada" (Machado, 1994, p.2).

\section{OUTROS DESAFIOS E ALGUNS LIMITES}

Como já dissemos, a "satisfação do cliente" é o ponto de partida e o ponto de chegada que confere sentido e legitima a busca da qualidade total. Constitui-se, pois, em sua referência principal. Tal referência (bem como seus derivados), quando transportada para a educação, aponta para a necessidade de reflexões adicionais. 
Supondo o aluno como "cliente" e sua satisfação o ponto de partida e o ponto de chegada do processo educacional, é evidente (aliás, em qualquer modelo e nao apenas nas balizas da qualidade total) que as demandas sociais mais amplas devem ser conhecidas; as necessidades e expectativas individuais precisam ser identificadas; os educadores devem assumir responsabilidade pelos resultados de seu trabalho, bem como definir metas viáveis e realistas; e, finalmente, todo o processo necessita ser sistematicamente controlado por procedimentos de avaliação, para a orientação da ação e para o planejamento de ajustes.

No entanto, as escolas geralmente operam com pouca ou nenhuma definição de seus objetivos de aprendizagem e com precários métodos de construção curricular. Além disso, em virtude das ineficientes condições de formação inicial e da contínua falta de apoio pedagógico, os professores encontram grandes dificuldades para formular estratégias eficazes de ensino. Somando-se a esses fatores, as deficientes práticas de avaliação acentuam o alheamento da cultura vivida pela escola em relação às reais condições sociais e às experiências cognitivas e existenciais de seus alunos; e mais, reforçam a incongruência entre o que se ensina e as efetivas necessidades educativas, especialmente daqueles com maiores dificuldades de inserção sociocultural.

Daí, ser importante entender que no significado de qualidade total, embora se explicite a necessidade de ajustes, de "sintonia fina", de levar em conta as diferenças culturais, a flexibilidade e a autonomia da escola, está embutida também a ideologia do consenso. Tendo como referência a solidariedade, idealiza-se a ausência de conflitos (nas instituições de ensino) e aposta-se num empenho solidário, por parte dos envolvidos, em busca de objetivos comuns.

A partir desses pressupostos, preconiza-se no Plano Decenal de Educação para Todos a reorganização da educação a partir de instrumentos de participação, em parceria, e modos de relacionamento capazes de formar o cidadão para o pluralismo, para o senso de tolerância, de solidariedade 
e de solução pacífica de conflitos (MEC, 1994, p.21). Sob o argumento de que tais padrões de conduta são requeridos para o aperfeiçoamento democrático, já que "desafiam o formalismo e a alienação dos programas escolares" (idem, ibidem), aposta-se na edificação de propostas educacionais "objetivas" e na planificação controlada.

Mas disso resulta exatamente o contrário, formalismo e alienação são coisas completamente diferentes. E certo que se rejeite o formalismo em busca da qualidade do ensino. Mas, tal providência não garante a exclusão de propostas alienantes que impedem o desvelamento do concreto e que negligenciam a importância de se levar em conta as contradições, os conflitos, os dissensos e as discordancias.

Para que não sejamos vítimas de ilusões simétricas, devemos encarar com mais realismo (e menos euforia) os possíveis obstáculos que, com certeza, dificultarão a implementação global de propostas idealizadas e ancoradas nos pilares da chamada "terceira revolução industrial", que, em nome da "modernidade", prevê sua própria sustentação em comportamentos éticos e solidários.

Assim como a análise da tão anunciada modernização brasileira inclui o conhecimento do contexto no qual foi operada a revolução tecnológica e uma reflexão acerca das disparidades que diferenciam as dinâmicas econômicas entre o centro-norte e a periferia dependente, da mesma forma, a proposição de conteúdos universalistas deve ser examinada diante da noção de ética.

A oferta de conteúdos universalistas, neutros, normativos e abstratos pode favorecer o acesso aos conhecimentos disponíveis, mas é insuficiente para permitir a leitura do mundo e para o desenvolvimento da interpretação crítica da realidade, principalmente no que diz respeito à compreensão das origens históricas e do jogo de interesses que perpetuam e mantêm as desigualdades instaladas.

Nesse sentido, a formação profissional deveria ser dimensionada a partir de uma dupla ótica. Por um lado, é importante capacitar o trabalhador para enfrentar os desafios de seu tempo. Ou seja, trata-se de 
instrumentá-lo para que possa fornecer respostas às exigências do mercado, proporcionando-lhe a aquisição de conhecimentos gerais e específicos e o domínio de habilidades flexíveis e adequadas às novas formas de produção e de gestão. Por outro lado, trata-se de rejeitar a artificialidade da suposição de que, necessariamente, deve haver coincidência entre os objetivos dos patrões e dos empregados para o alcance do "bem comum" e da qualidade total.

A cooptação nesse sentido é desastrosa e falsificadora. No discurso e no "texto", preconiza-se a importância de atitudes e habilidades, tais como capacidade de trabalhar em equipe, solidariedade, autonomia, criatividade, potencialidade para tomar decisões, co-gestão participativa, flexibilidade e espírito de iniciativa.

No concreto e no contexto, sedimentam-se, cada vez mais, a "cultura do controle" e a permanência de relações hierarquizadas, no bojo das quais a noção de "problema" se resume à não-conformidade com os padrões estabelecidos. Padrões que valorizam a disciplina, a subserviência, o cumprimento de ordens e a aceitação silenciosa das determinações superiores.

E muito provável que a competitividade como meta, a gratificação por mérito, a exigência do sigilo em relação aos salários, o enfraquecimento dos sindicatos e a livre negociação entre empresários e trabalhadores desencadeiem distorções, para a maioria dos trabalhadores, muito mais desastrosas do que aquelas já conhecidas.

Mesmo admitindo a emergência da ética como princípio regulador de negociações, há que se considerar a natureza individualizada de suas bases e o pragmático desequilíbrio que se estabelece entre seus pólos de negociação. De um lado, os empregados otimizando a possibilidade de inserir o País no contexto da economia globalizada. De outro, a exclusão incontrolável (e cada vez maior) de grande parte da população mundial do mercado de trabalho.

Nessas condições, como se encaixa o discurso acerca do resgate da ética enquanto caminho a ser trilhado? 
Do ponto de vista etimològico, a Ética é concebida como a parte da filosofia que estuda os valores morais e as normas ideais da conduta humana. Em termos processuais, e incrustada na parte prática da filosofia social, passa a ser um dispositivo normativo ao qual se devem ajustar as relações entre os diversos membros da sociedade.

A despeito da inquestionável importância da ética, enquanto princípio regulador desses ajustes, impõe-se antever "os efeitos a médio prazo dessa turba crescente de marginalizados pelo processo histórico, quando seu alcance ainda é dificil de ser mensurado" (Dupas, 1994). Inclusive porque alguns sintomas já estão à vista de todos e podem ser constatados em diferentes níveis; em uma perspectiva mais ampla, são eles: a eclosão de fundamentalismos, o renascimento do neofascismo, a multiplicação de organizações mafiosas, as migrações de povos inteiros e guerras civis por toda parte (idem, ibidem).

No cotidiano das relações interpessoais, o sistemático ataque ao corporativismo e o conseqüente apelo à solidariedade, embasado em princípios éticos, escamoteiam evidentes conflitos.

$\mathrm{Na}$ acepção do termo, solidariedade significa uma comunidade total de interesses e de responsabilidades. No entanto, por sua imposição indiscriminada e por escamotear conflitos de interesses, as práticas "solidárias" tendem a ser deslocadas. Nas definições das chamadas "fórmulas de sucesso", os "bem-sucedidos", através de apoios declarados ou mediante omissões e silêncios, acabam por perder suas genuínas identidades sociais. Presas fáceis, ao invés de incorporarem também o caráter contraditório das relações de trabalho na sociedade contemporânea, provavelmente estarão mais inclinados a desenvolver somente comportamentos de ajustamento e de observância às determinações das lideranças, para que possam se sentir correspondendo ao prescrito e, portanto, legitimados e recompensados.

\section{Referências bibliográficas}

BRASIL. MEC. Plano Decenal de Educação para Todos 1993-2003. Brasília: Secretaria de Educação Básica, 1994. 
CASASSUS, J. Modernidade educativa e modernização educacional. Cadernos de Pesquisa, São Paulo, n.87, p.3-96, nov. 1993.

DUPAS, Gilberto. Folha de S. Paulo, 2 dez. 1994. Cad. 1 p.18.

FOLHA DE S. PAULO. São Paulo, 13 mar. 1994. Cad. 4 p.8.

FRANCO, Maria Laura P. B. Ensino médio, desafios e reflexões. Campinas: Papirus, 1994. cap. 6

MACHADO, Lucila. Controle de qualidade total. Extra-Classe em Revista, v.2, n.1, out. 1993.

Controle de qualidade total e educação. Texto apre sentado no Seminário sobre Qualidade Total da Educação, promovido pelo Centro de Estudos dos Sindicais e realizado em São Paulo, de 6 a 8 de maio de 1994.

MEDICI, André. Qualidade nas escolas: realidade ou utopia? mimeo. [S.1.], 1993.

RISOPATRON, Verônica. El concepto de calidad de la educación. Santiago do Chile: OREALC/UNESCO, 1991.

VEJA. São Paulo, 25 ago. 1993.

Recebido em 3 de março de 1995.

Maria Laura Puglisi Barbosa Franco, doutora em Psicologia da Educação pela Pontifícia Universidade Católica de São Paulo (PUC-SP), é professora titular da referida universidade, na área de Psicologia da Educação - Fundamentos da Educação. 
This article discusses the concept of quality education, its relation to the significance of Total Quality, and its implications on education. It questions the quality-quantity dichotomy in the scope of the Brazilian educational system. It spells out the link between the indicators implicit in the quality education concept and the demands brought by the new production processes and the requirements entailed in the education of the professional.

Cet article présente une discussion du concept de Qualité de I 'Enseignement, son rapport avec la signification de Qualité Totale et ce qu 'il implique dans le domaine de l 'éducation; une mise en question de la dichotomie quantité/qualité dans le cadre du système d'éducation brésilien; la mise en évidence du lien qui se forme entre les indicateurs implicites dans la conception de l'enseignement de qualité face aux demandes issues des nouveaux processus de production et de leurs exigences vis-à-vis de la formation professionnelle.

El artículo discute el concepto de cualidad de la enseñanza, su relación con el significado de Cualidad Total y sus implicaciones en la educación; cuestiona la dicotomía cuantidadx cualidad en el ámbito del sistema educacional brasileño; expone el vínculo que se establece entre los indicadores implícitos en la concepción de la ensenanza de cualidad con las demandas provenientes de los nuevos procesos de producción y sus exigencias para la formación profesional. 